\title{
TRÊS CENÁRIOS EDUCACIONAIS PARA O FUTURO: LICCÕES DA SOCIOLOGIA DO CONHECIMENTO
}

MICHAEL YOUNG JOHAN MULLER

TRADUÇÃO: Jessé Rebello REVISÃO TÉCNICA: Adriana Bauer

* Artigo traduzido do original: "Three educational scenarios for the future: lessons from the sociology of knowledge", publicado no European Journal of Education, v. 45, n. 1 p. $11-27,2010$

\section{RESUMO}

O presente texto se baseia em enfoques oriundos da sociologia do conhecimento e, em vista deles, constrói três cenários para o futuro da educação nas próximas décadas. 0 principal foco recai sobre uma das mais cruciais questões enfrentadas pelos formuladores de políticas educacionais - a relação entre a escola e o conhecimento da vida cotidiana ou do senso comum. As diferentes possibilidades sobre como as fronteiras entre conhecimento escolar e não escolar devem ser abordadas são expressas em três cenários - "fronteiras dadas", "um mundo sem fronteiras" e a ideia da "manutenção das fronteiras como condição para seu cruzamento". As implicações educacionais de cada cenário são exploradas e argumenta-se em favor do terceiro deles. Consideram-se também os fatores que podem fazer com que um ou outro desses cenários domine nas politicas educacionais.

PALAVRAS-CHAVE SOCIOLOGIA DO CONHECIMENTO - REALISMO SOCIAL • CURRÍCULO • CONHECIMENTO • FRONTEIRAS DISCIPLINARES. 


\section{TRES ESCENARIOS EDUCACIONALES PARA EL FUTURO: LECCIONES DE LA SOCIOLOGÍA DEL CONOCIMIENTO}

RESUMEN

El presente texto se basa en enfoques oriundos de la sociología del conocimiento $y$ en función de ellos construye tres escenarios para el futuro de la educación en las próximas décadas. El principal enfoque recae sobre una de las más cruciales cuestiones que enfrentan los formuladores de políticas educativas - la relación entre la escuela y el conocimiento de la vida cotidiana o del sentido común. Las distintas posibilidades sobre cómo abordar las fronteras entre el conocimiento escolar y el no escolar se expresan en tres escenarios - "fronteras dadas", "un mundo sin fronteras" y la idea del "mantenimiento de las fronteras como condición para su cruce". Se exploran las implicaciones educacionales de cada escenario y se argumenta en favor del tercero de ellos. También se consideran los factores que pueden hacer que uno u otro de dichos escenarios predomine en las políticas educacionales.

PALABRAS CLAVE SOCIOLOGÍA DEL CONOCIMIENTO - REALISMO SOCIAL • CURRÍCULO • CONOCIMIENTO • FRONTERAS DISCIPLINARES.

\section{THREE EDUCATIONAL SCENARIOS FOR THE FUTURE: LESSONS FROM THE SOCIOLOGY OF KNOWLEDGE}

ABSTRACT

This article draws on social realist approaches in the sociology of knowledge and in light of them constructs three scenarios for the future of education in the next decades. The primary focus of the paper is on one of the most crucial questions facing educational policy makers - the relationship between school and everyday or common sense knowledge. The different possibilities for how the school/non-school knowledge boundaries might be approached are expressed in three scenarios 'boundaries treated as given', 'a boundary-less world' and the idea of 'boundary maintenance as a condition for boundary crossing'. The curriculum implications of each are explored and the article makes the case for the third scenario. The factors likely to make one or other scenario dominate educational policy in the next 20-30 years are also considered.

KEYWORDS SOCIOLOGY OF KNOWLEDGE • SOCIAL REALISM • CURRICULUM • KNOWLEDGE・DISCIPLINARY BOUNDARIES. 


\section{INTRODUÇÃO}

O presente artigo aborda a questão de "futuros educacionais possíveis", não enquanto um exercício de previsão futurística, mas por meio de uma análise das atuais tendências em políticas educacionais (YOUNG, 2009a). Entretanto, "pensar futuros" não tem sido uma das principais vertentes de pesquisa e teorização na sociologia da educação ou nos estudos da educação em geral. Como resultado, tal atividade tem sido amplamente relegada a especialistas em educação, que prestam pouca atenção explícita tanto aos debates sociológicos sobre as atuais mudanças sociais, frequentemente ocultadas por termos como globalização e sociedades do conhecimento, quanto a como a questão do conhecimento é entendida dentro desses debates (YOUNG, 2009b; MULLER, 2009). A abordagem típica desse tipo de pensamento consiste em identificar aquilo que se observa com o crescente descompasso entre as escolas e algumas das mudanças globais na sociedade mais ampla discutidas em outros artigos desta Edição Especial. ${ }^{1}$ Essas abordagens tendem a se preocupar com a questão de como o sistema da educação formal, e as 
escolas em particular, quase que sistematicamente resistem a tais mudanças. Além disso, as premissas desse "pensar futuros" tendem a assumir que certas mudanças sociais mais amplas são não apenas inevitáveis, mas positivamente benéficas à humanidade, e que a escolarização do futuro terá que acompanhá-las. Esse "acompanhar" é invariavelmente visto como tranquilo.

O futuro da escolarização nesses cenários reside em abandonar o que é visto como seu passado medieval e adaptar-se às tendências globais de maior flexibilidade e abertura à mudança por parte dos indivíduos; consequentemente, prevê-se que a escolarização se tornará cada vez menos diferenciada em relação a outras instituições sociais. Os dois exemplos dessa forma de "pensar futuros" mostrados a seguir, não atípicos, mas sob vários aspectos bastante diferentes, ilustrarão esse ponto. O primeiro exemplo é de Peter Mortimore, ex-diretor do Institute of Education - University of London. Em uma coluna no Guardian, ele escreveu:

Diversas mudanças afetam as sociedades ocidentais. Novos cidadãos estão importando diferentes tradições culturais e religiosas; famílias assumem novas configuracões; horários de trabalho se tornam mais diversificados e a internet toma conta de nossas atividades de compras, diversão e informação [...]. As pessoas se tornaram mais conscientes dos direitos individuais, porém são menos respeitosas com relação às autoridades [...]

Mesmo as escolas inglesas [...] custam a mudar [...] apenas os diretores de escola mais confiantes escapam à inibição de experimentar novas abordagens.

Muitos aspectos da escolarização mudaram [...] a abolição de punições físicas e a introdução de um currículo nacional [...]. Mas não deveria haver mudanças mais fundamentais na forma como alunos são educados, de modo a combinar melhor com a maneira como as pessoas vivem hoje? (itálicos nossos). Não se deveria dar maior destaque a questões como a sustentabilidade do meio ambiente, os perigos da obesidade, das drogas e da Aids e, em vista dos eventos atuais, à educação financeira?. (MORTIMORE, 2008) 
Nosso segundo exemplo, mais acadêmico, vem de um artigo publicado pelo reconhecido sociolinguista Gunther Kress (2008), que argumenta que as mudanças sociais globais põem em questão a adequação de:

- nossos mitos dominantes sobre educação, derivados de um passado já bastante distante, e

- nossos pressupostos sobre a homogeneidade do público da educação e [...] sobre a segurança ontológica/epistemológica do "conhecimento".

A escola, segundo Kress (2008), é cada vez mais deixada “sem seus propósitos legitimadores". Ela enfrenta uma

[...] mudança emblemática na ênfase da retórica educacional do ensinar para o aprender [...]. Nenhuma instituição regula (mais) o que deve ser aprendido [...] nenhum currículo definido existe [...] e o conhecimento é feito pelos aprendizes em relação a suas necessidades, como ferramentas para solucionar os problemas encontrados por eles em suas vidas. (acréscimo nosso entre parênteses)

Kress (2008) afirma ainda que

[...] uma parcela significativa dos jovens está alienada da escola - eles não consideram mais a escola como algo relevante para $[. .$.$] o mundo como eles o experienciam [...].$ O que a escola de fato oferece [...] não é mais de interesse para esses jovens [...] a responsabilidade (pela transição da escola ao trabalho) agora recai sobre os próprios jovens.

Mortimore aponta para uma maior ênfase em um possível "currículo do futuro", para temas "relevantes" e contemporâneos. Seu argumento lembra aquele da QCA Qualifications and Curriculum Authority - em suas novas propostas curriculares para o ensino de ciências, transferindo o peso dado ao conteúdo para aquilo que pode ser relevante e ter significado pessoal para os alunos. Entretanto, nem as QCA inglesas nem Mortimore nos dizem como esses temas poderiam ser abordados pelos professores de forma a ir além de um simples compartilhar de opiniões sobre temas como a epidemia de HIV/Aids, que envolve complexos conjuntos de 
conhecimentos especializados em campos tais como a microbiologia.

Kress nos conta que o futuro já chegou e que são os educadores que, ao contrário dos jovens, estão cegos pela tradição e não veem isso. Se o futuro no qual ele vê as escolas se adaptando e respondendo às "demandas" da próxima geração realmente lhe trará entusiasmo e protagonismo, é outra questão.

Neste artigo nos apoiaremos em algumas ideias da sociologia do conhecimento ${ }^{2}$ para contar uma história bastante diferente acerca da escolarização e de seus possíveis futuros em uma sociedade cada vez mais globalizada. Argumentaremos que um foco no caráter conservador das instituições educacionais, em sua resistência a mudanças e na sua perpetuação de formas anacrônicas de autoridade e de prioridades curriculares arcaicas que guardam pouca relação com as demandas do mundo contemporâneo constitui, sob diversos aspectos, uma base limitada para se "pensar o futuro". Em primeiro lugar, ele falha em distinguir entre o papel inerentemente "conservador" das escolas, enquanto instituições envolvidas na "transmissão de conhecimento" de uma geração para outra, e o "conservadorismo" como tendência de todas as instituições a resistirem à mudança e manterem privilégios dos grupos mais poderosos. É preciso diferenciar essas duas formas de conservadorismo se queremos enxergar como as escolas continuarão a transmitir conhecimento (e valores) entre gerações nas sociedades de hoje, que mudam rapidamente. Em segundo lugar, um foco nas mudanças na sociedade em geral, e em como as escolas devem adaptar-se a elas, subestima em que medida essas instituições, como agentes de transmissão cultural, seguirão uma lógica própria que poderá ir de encontro às demandas mais imediatas dos jovens em nome de seus interesses no longo prazo.
2 A abordagem do sociorrealismo é uma escola de pensamento da Sociologia da Educação que é relativamente nova. Autores que têm trabalhado nessa perspectiva, individual ou coletivamente, têm se preocupado com o "problema do conhecimento", principalmente com as relações entre conhecimento, educação e currículo escolar e com a natureza do conhecimento a ser ensinado nas escolas. Eles reconhecem o caráter social do conhecimento como intrinsecamente implicado na sua construção, mas em contraste com as abordagens construtivistas e pós-estruturalistas, com suas implicações relativistas, os autores dessa linha de pensamento defendem que há um "conhecimento melhor" - às vezes referido como conhecimento poderoso - que deveria estar acessivel para todos os alunos. De fato, segundo Young o sociorrealismo emerge como uma tentativa de corrigir os extremos do sócio-construtivismo - como expressado na Nova Sociologia da Educação e no seu próprio trabalho dos anos 1970, e das abordagens pós-modernas. Ao resgatar ideias de Durkheim sobre o papel do conhecimento no currículo e o pensamento de Bernstein sobre as estruturas de conhecimento, teóricos do sociorrealismo como Young e Muller distinguem conhecimento e experiência, defendendo o papel central que o primeiro deveria ter no currículo escolar. Para mais informações veja Young $(2008,2001)$, Moore (2013) e Moore e Muller (1999) (nota do revisor técnico).

\section{EDUCAÇÃO E SOCIOLOGIA DO CONHECIMENTO}

A pesquisa em sociologia do conhecimento tem tido uma influência significativa, ainda que controversa, sobre os debates acerca da educação na Grã-Bretanha e em outros lugares, pelo menos desde a década de 1970. Embora essa 
influência possa ser localizada a partir da indicação de Karl Mannheim para a Cátedra de Sociologia da Educação no Institute of Education - University of London - em 1946, não foi senão a partir de 1970 que as ideias sociológicas sobre o conhecimento passaram a ser levadas a sério nos estudos educacionais. Mais do que isso, foi somente na década passada que uma tradição de pesquisa marcada pelo realismo social, objeto deste texto, começou a emergir na Grã-Bretanha (MOORE, 2007; YOUNG, 2008), na África do Sul (MULLER, 2000; GAMBLE, 2006), na Austrália (WEELAHAN, 2007) e em vários países da América Latina e da Europa, como Portugal e Grécia. A principal fonte para esse trabalho tem sido as ideias/ teorias do sociólogo britânico Basil Bernstein, falecido em 2001, e a inspiração por ele encontrada nas ideias do sociólogo francês Émile Durkheim, que escreveu um século atrás. Contudo, essa tradição emergente na sociologia da educação também se baseou em uma série de desenvolvimentos mais amplos em (i) teoria sociológica (COLLINS, 2000; BOURDIEU, 2004; HALL; JARVIE, 1996); (ii) sociologia da ciência (COLLINS; EVANS, 2007); (iii) filosofia (NORRIS, 2006; TILES, 1984); e (iv) linguística - o Sydney Systematic Functional Linguistics Group, que relaciona explicitamente a noção de conhecimento às fontes da linguagem (CHRISTIE; MARTIN, 2007).

Este texto começa pela localização das origens intelectuais de uma sociologia do conhecimento especificamente realista nos trabalhos de Émile Durkheim (1984) do início do século XX. Entretanto, sugerimos que sua emergência como uma vertente de pesquisa dentro da sociologia da educação nas últimas duas décadas foi tanto uma resposta crítica a outros desenvolvimentos no campo mais amplo da pesquisa educacional e na política educacional como uma redescoberta da tradição social realista da corrente sociológica. Esses desenvolvimentos em pesquisa social e educacional incluem:

i. perspectivas do construtivismo social/pós-modernismo acerca do conhecimento e da verdade encontradas em muito da recente sociologia da educação, assim como, de modo mais amplo, nas humanidades e ciências sociais (KRONMAN, 2007); 
ii. teorias socioculturais da aprendizagem que têm, implícita e, por vezes, explicitamente, dominado a pesquisa educacional em uma gama de áreas, tais como a ciência da educação, o aprendizado baseado no trabalho e os estudos da diversidade (BOGHOSSIAN, 2007).

Esses desenvolvimentos teóricos têm sido acompanhados por vários desenvolvimentos nas políticas, que têm suas raízes nas recentes políticas neoliberais e na celebração dos mercados. Exemplos incluem:

a. o foco cada vez mais "instrumental" das políticas educacionais que, conceitualmente, embora não politicamente, têm muitas afinidades com (i) e (ii) acima. Por exemplo, torna-se cada vez mais difícil defender publicamente a "educação por si mesma", isto é, "a promoção do desenvolvimento intelectual dos jovens";

b. o entusiasmo acrítico das agências de fomento e dos formuladores de políticas pelo potencial educacional das tecnologias digitais, e o desafio que isso representa para as instituições educacionais especializadas e para o papel dos professores (KEEN, 2007; SHARPLES, 2007).

As implicações particulares das ideias sociológicas discutidas neste artigo são uma consequência do reconhecimento (a) da necessária objetividade do conhecimento como condição para qualquer tipo de investigação ou previsão confiável sobre o futuro e (b) de que o conhecimento emerge dos - mas não é redutível aos - contextos nos quais ele é produzido e adquirido. Ao mesmo tempo, uma abordagem social realista implica uma abordagem explicitamente histórica ao pensamento sobre tendências futuras. Sem essa abordagem histórica ao conhecimento, as previsões tendem a constituir pouco mais do que extrapolações a partir do presente, como se o presente não tivesse ele mesmo uma história.

O dilema colocado pelo reconhecimento de que o conhecimento é, ao mesmo tempo, "objetivo" e histórico não é novo e nos remete pelo menos a Hegel. Ele reside no cerne da sociologia 
3 Os autores referem-se à "pedagogia" como os processos e práticas relacionados aos processos e abordagens de ensino e aprendizagem, e não à disciplina que lida com as teorias e práticas educacionais (nota do revisor do conhecimento que foi estabelecida um século atrás por Durkheim, Weber e Mannheim, tendo sua continuidade mais recentemente por Habermas, Randall Collins e outros.

Argumentamos que é importante distinguir o que denominamos teorias "sociais realistas" do conhecimento das duas abordagens que estabeleceram os termos dos debates mais recentes sobre conhecimento nas ciências sociais e em filosofia. A primeira dessas abordagens - simbolizada talvez pelo positivismo lógico e seus paralelos empiristas nas ciências sociais - pode ser caracterizada por invocar uma epistemologia associal ou "subsocializada" que define conhecimento como um conjunto de proposições verificáveis e os métodos para testá-las. Ela trata sua produção social em contextos históricos específicos e dentro das fronteiras das disciplinas particulares como implícita ou dada. A segunda abordagem, que surgiu em resposta direta à primeira - a que denominamos como "supersocializada" -, minimiza o caráter proposicional do conhecimento e reduz questões epistemológicas a um “quem sabe?” e à identificação dos portadores do conhecimento e de suas práticas. Uma teoria social realista, por sua vez, enxerga o conhecimento como algo que envolve tanto conjuntos de conceitos sistematicamente relacionados e métodos para sua exploração empírica, como as "comunidades de investigadores" cada vez mais especializadas e historicamente localizadas (uma ideia expressa primeiramente pelo filósofo americano Charles S. Pierce), com seus compromissos particulares com a busca da verdade e com as instituições sociais nas quais elas se encontram.

\section{UMA ABORDAGEM SOCIAL REALISTA AO CONHECIMENTO} E SUAS IMPLICAÇÕES EDUCACIONAIS

O caráter emergente, irredutível e socialmente diferenciado do conhecimento tem, a nosso ver, implicações educacionais potencialmente profundas. Exemplos de tais implicações, que mereceriam um artigo dedicado a elas, e que podem aqui ser apenas listados, incluem a importância:

- da distinção entre currículos e pedagogia; ${ }^{3}$

- da "não arbitrariedade" das fronteiras entre domínios do conhecimento e entre conhecimento escolar e não escolar; 
- da base "objetiva" de autoridade e profissionalismo dos professores e outros especialistas;

- da inescapável natureza hierárquica da pedagogia;

- das condições para - e definições de - criatividade e inovação;

- das limitações epistemológicas do escopo das políticas de ampliação da participação e promoção da inclusão social;

- das limitações das "habilidades genéricas" como modelo para uma "educação geral";

- da importância crucial dos "conteúdos específicos" e de distinguir entre "conteúdo do assunto" - como o componente relativamente estável do conhecimento sobre um assunto - e "informação" (como o que está disponível na internet) que jamais é estável e sempre muda.

Perpassa todos esses temas uma ênfase na irredutível diferenciação do conhecimento. O conhecimento é estruturado, em parte independentemente de como o adquirimos, e os campos do conhecimento diferem em sua coerência interna, em seus princípios de coesão e em seus procedimentos para produção de novos conhecimentos. Essas diferenças internas são refletidas nas diferentes formas de relação social entre agentes que atuam nas instituições de cada campo: relações de conhecimento e relações sociais variam conjuntamente.

A distinção entre os conservadorismos "estrutural" e "social” das instituições educacionais referidos anteriormente é importante para identificar as "limitações" epistemológicas do desenho curricular. $\mathrm{O}$ realismo social enxerga o primeiro deles como uma condição para o progresso e inovação, e para a aquisição de conhecimento. Ele é, porém, facilmente confundido, especialmente por aqueles que se veem como educadores radicais, com o "conservadorismo social" das instituições educacionais que preservam o poder e os privilégios de grupos específicos. A famosa crítica de Gramsci às reformas Gentilianas da educação italiana na década de 1920 deixa essa distinção bem clara. Ele defende o conservadorismo 
estrutural do antigo currículo contra as mudanças "progressistas" propostas por Gentile, as quais excluiriam as classes populares do acesso ao conhecimento por meio de uma forma espúria de "vocacionalismo" (ENTWISTLE, 1979).

A segunda distinção que desejamos fazer é entre os dois sentidos da ideia de educação como "transmissão cultural". Na linguagem cotidiana, transmissão se refere a "passar adiante" - um sinal, uma mensagem ou uma doença. A educação também envolve um "passar adiante", de conhecimento, ou, mais genericamente, de uma cultura. Todavia, enquanto o sentido comum da transmissão de um sinal é um movimento de mão única, no qual o receptor é o recipiente passivo, a transmissão cultural ou de conhecimento associada com a educação é um processo bem mais complexo que envolve o papel ativo dos "recipientes" em tornar seu esse conhecimento. A literatura especializada peca por polarizar esses dois sentidos da transmissão. Um exemplo é o conhecido e, em vários aspectos, perspicaz ensaio de Anna Sfard (1998) sobre teorias da aprendizagem. Sua análise deixa por resolver a polarização, pois a autora trata a aprendizagem como um processo genérico separado "daquilo que se aprende". Em contraste, argumentamos que "aprender" implica sempre "aprender algo"; há aqui um paralelo com o argumento de Alastair MacIntyre (MACINTYRE; DUNNE, 2002) de que o ensino como um conceito genérico é vazio - sempre "ensinamos algo". Disso decorre que o aprender necessariamente envolve a transmissão cultural ou a transmissão de conhecimento. A transmissão de cultura, crescentemente, porém não exclusivamente, por meio de instituições educacionais, de geração a geração, é o que distingue "sociedades" humanas das animais, e torna possível à primeira reproduzir o progresso. A transmissão cultural é sempre reprodutiva e potencialmente, embora não necessariamente, progressista.

Argumentamos que a abordagem realista social, com sua prioridade no conhecimento que é (ou não) transmitido no currículo, embora divirja de boa parte do pensamento educacional contemporâneo que foca essencialmente o aprendiz e sua experiência, oferece uma base mais confiável para identificar tendências subjacentes e imaginar futuros 
possíveis ou, na frase evocativa de Eric Olin Wright, "utopias reais" (WRIGHT, 2006).

Ao enfatizar a diferenciação social tanto de conhecimentos como de instituições, a abordagem do realismo social desafia a noção amplamente aceita de que fronteiras são sempre barreiras a serem transpostas, em vez de serem também condições para a inovação e para a produção e aquisição de novo conhecimento. Como afirma Bernstein (2000), fronteiras desempenham um importante papel na criação da identidade do aprendiz e são, portanto, condições para a aquisição de "conhecimento poderoso", bem como barreiras ao aprendizado. Segue-se que:

- o futuro global da educação não será necessariamente de maior flexibilidade, portabilidade e transparência;

- continuará a ser importante diferenciar o aprendizado nas escolas, faculdades e universidades do aprendizado em casa, no local de trabalho e em comunidades;

- a experiência não pode, ela própria, ser a única ou principal base do currículo; e

- como os aprendizes não podem, de fato, "construir" seu próprio conhecimento (porque, como diz Foucault incisivamente, “eles não podem saber aquilo que não sabem”), o papel dos professores não pode ser reduzido ao de guias e facilitadores em vez de fonte de estratégias e especialização.

\section{TRÊS CENÁRIOS PARA O FUTURO}

O papel das fronteiras e a diferenciação social dos conhecimentos são os princípios-chave que extraímos da sociologia do conhecimento para identificar possíveis cenários futuros. Com essas hipóteses em mente, a próxima seção explora as implicações de três possíveis cenários futuros para os próximos 20-30 anos. 


\section{OS TRÊS FUTUROS (OU CENÁRIOS PARA O FUTURO)}

Futuro 1 - As fronteiras são dadas e fixas - o "Futuro" é associado a um conceito naturalizado ou "subsocializado" de conhecimento;

Futuro 2 - O fim das fronteiras - o "Futuro" é associado a um conceito "supersocializado" de conhecimento;

Futuro 3 - Manutenção das fronteiras como condição para seu cruzamento. Neste "Futuro" é a relação variável entre manutenção e cruzamento de fronteiras que constitui a condição para a criação e aquisição de novo conhecimento.

4 Eles jamais são totalmente imunes a influências da classe trabalhadora e de outros movimentos
FUTURO 1 - FRONTEIRAS DADAS E FIXAS - UM CONCEITO NATURALIZADO OU “SUBSOCIALIZADO" DE CONHECIMENTO

Todo sistema de educação em massa tem sua principal, porém não única, origem em um sistema de elite; ${ }^{4}$ ou seja, em um sistema para a transmissão de conhecimento cultural de elite aos "poucos selecionados", por vezes aos "eleitos”, que são usualmente os filhos das classes dominantes. Tais sistemas envolvem a iniciação de tais classes nas tradições do conhecimento dominante que as mantêm como dominantes. Essas tradições são majoritariamente estáticas, visto que suas fronteiras são fixadas por imperativos sociais que sobrepujam as condições para o conhecimento e seu dinamismo inato, fecundidade e abertura às mudanças. Elas são socialmente conservadoras nesse sentido estático dual. No final do século XIX (pelo menos na Europa), três forças sociais democratizantes romperam com essa matriz elitista. A primeira foi a demanda generalizada vinda das camadas populares por acesso à escolarização - isto é, uma demanda pela sua massificação. A segunda foi a explosão de conhecimentos acerca dos mundos natural e social. Essa explosão de "conhecimento poderoso" desafiou a ideia tradicional de currículo como "conhecimento dos poderosos" e, lenta e inexoravelmente, eclipsou os cânones ultrapassados do antigo sistema de elite. Bem mais tarde, as prioridades dos movimentos sociais, tanto feministas, quanto pós-colonialistas, começaram a ser incorporadas. Em todos os países, os sistemas educacionais de elite tiveram que lidar com esse triplo 
desafio. O Futuro 1 representa as tentativas de dar continuidade ao sistema de elite, ao mesmo tempo em que se abre acesso, tão marginalmente quanto possível, às forças sociais mais amplas.

Em algum momento, a expansão dos sistemas de elite esbarra em limitações intrínsecas, com as quais ela precisa lidar. Essas limitações incluem:

i. a incapacidade dos mercados de trabalho para absorver mais trabalhadores treinados dentro dos mesmos moldes conservadores;

ii. as limitações de um sistema de escolarização em massa para iniciar com igual sucesso todas as crianças nas tradições do conhecimento de elite, que depende de um lar de classe média como um fator adjuvante crucial e condição para aquele sucesso.

Em graus bastante variáveis, todos os sistemas de escolarização em massa fracassaram em superar essas limitações e falharam em "compensar" a distribuição desigual de condições para o sucesso que eles mesmos criaram.

A atitude padrão no enfrentamento desse permanente escândalo tem sido uma ou outra forma de sistemas de trajetórias ou rotas educacionais, que preservam a trajetória de elite para a elite e para uma pequena fração da massa. Para o restante, são providas uma ou mais trajetórias vocacionais, que nas suas piores formas representam apenas versões "estupidificadas" do conhecimento de elite - alfabetização matemática, comunicações ou "ciência popular", por exemplo (YOUNG, 2008; WHEELAHAN, 2007). Estes assim chamados currículos "vocacionais" se tornam procedimentalizados, mormente com o advento da tecnologia - tanto o "Fordismo digital" de Lauder (LAUDER et al., 2008) quanto o cognitariado de Newfield (2010) mostram que esse procedualismo não é limitado aos desfavorecidos -, e o acesso ao "conhecimento poderoso" é vedado às massas. O resultado é um sistema claramente estratificado em camadas sociais, com a escolarização como seu principal instrumento. Seu destino é ser eternamente visto como injusto e, portanto, não aceito. Nesse sentido, o Futuro 1 é uma receita para a divisão 
social, desigualdade, infelicidade e conflito. O mecanismo que produz a injustiça é percebido por aqueles que o opõem como sendo a forma do currículo de elite - manifesto, estritamente estipulado e ritmado. Sua delimitação é vista como o problema principal, e a condição para maior justiça social e menor desigualdade, ao menos para os proponentes do $\mathrm{Fu}$ turo 2, é a eliminação dessas fronteiras.

No cenário Futuro 1, há poucas fontes de inovação dentro do sistema educacional. A educação e o contexto mais amplo continuarão a existir como dois mundos paralelos. Podemos, entretanto, prever uma crescente diferenciação baseada na localidade e no conservadorismo de tradições culturais, maiores divisões entre Norte e Sul e, por exemplo, entre diferentes tradições fundamentalistas culturais e religiosas. Tratar as fronteiras como dadas, e não como sociais, torna-se nesse cenário a base para manter e legitimar as relações de poder existentes e para restringir fontes de debates. Não há, por certo, formas puras do Futuro 1, nem mesmo em autocracias; todavia, seria um erro considerar que o Futuro 1 não tem futuro. Muitos elementos do Futuro 1 permanecem no sistema inglês, como indicado por Fitz, Davies e Evans (2006), e é provável que eles subsistam ainda por muito tempo. A pior situação que pode resultar desse cenário é expressa de forma estridente e evocativa em Clash of Civilisations (1998), de Samuel Huntington e, mais coloquialmente, na "Guerra ao Terror" de George W. Bush.

\section{FUTURO 2 - O FIM DAS FRONTEIRAS - UM CONCEITO "SUPERSOCIALIZADO" DE CONHECIMENTO}

Como já indicado, o Futuro 2 nasce de uma oposição "progressista" ao Futuro 1. Ele prevê um enfraquecimento contínuo das fronteiras, uma desdiferenciação dos conhecimentos e instituições, um esmaecimento dos setores do mercado de trabalho e uma maior ênfase em resultados genéricos - em vez de em entradas - como instrumentos de equalização e responsabilização. Elementos dos ideais do Futuro 2 podem ser vistos nos cenários sugeridos por Mortimore e Kress, aos quais nos referimos no início deste texto. $^{5}$ 
Á medida que essas tendências direcionadas ao aprendiz forem adotadas, acopladas à introdução generalizada das tecnologias digitais, veremos uma desprofissionalização do ensino em todos os níveis, e uma desespecialização da pesquisa. É uma tendência que enfrentará resistência das forças que apoiam o Futuro 1, mas que ganha terreno por toda a Europa e além dela.

O "instrumento de escolha" curricular por excelência daqueles que almejam o enfraquecimento das fronteiras e a desdiferenciação é a modularização, usando o termo em seu sentido mais amplo. Entre as expressões desse enfraquecimento de fronteiras, diversas combinações das seguintes ações são frequentemente encontradas:

- a "integração" das matérias escolares, à medida que as fronteiras entre as matérias e entre o conhecimento escolar e o conhecimento cotidiano são enfraquecidas;

- a estipulação do conteúdo curricular em termos genéricos, normalmente em termos de habilidades ou resultados - também como consequência do enfraquecimento das fronteiras entre as matérias escolares e os campos do conhecimento;

- a promoção da avaliação formativa sobre a avaliação somativa, à medida que os limites entre os índices de desempenho de diferentes aprendizes são enfraquecidos;

- a introdução de quadros de referência para uma qualificação nacional unificada, à medida que as fronteiras entre diferentes qualificações (especialmente entre a acadêmica e a vocacional) são enfraquecidas;

- a promoção do ensino facilitador em vez do ensino diretivo, à medida que as fronteiras entre especialistas e aprendizes novatos são enfraquecidas.

Nossa posição, conforme descrevemos acima, é a de que as fronteiras educacionais são sociais, porém reais, não arbitrárias; vale dizer, elas não podem ser dissolvidas, pelo menos no curto prazo, sem sérias consequências para a maioria, se não para todos os aprendizes. O que esses mecanismos de desdiferenciação provavelmente acarretarão não é a dissolução das fronteiras, mas a sua invisibilidade - uma 
$6 \cup \mathrm{m}$ exemplo é o influente sociólogo português Boaventura de Sousa Santos em sua "epistemologia dos conhecimentos ausentes", na qual ele propõe ir além do que ele vê como a "cegueira" da ciência ocidental. Eis como ele se refere a ela em um artigo no European Journal of Social Theory: "a epistemologia dos conhecimentos ausentes parte da premissa de que práticas sociais são práticas de conhecimento [...] (e de que) práticas não baseadas na ciência, em vez de serem práticas ignorantes, são práticas de conhecimentos alternativos rivais. Não há razão priori para favorecer uma forma de conhecimento em detrimento da outra" (SANTOS, 2001 tradução nossa) invisibilidade que é intensificada para os menos favorecidos. Isso significa dizer que os principais efeitos do Futuro 2, a despeito das melhores intenções dos seus defensores - aqueles que apoiam uma pedagogia progressista em suas diversas variantes -, são os de tornar os contornos do conhecimento e do aprendizado invisíveis precisamente para os aprendizes que essa pedagogia tencionava beneficiar - a saber, os aprendizes, invariavelmente oriundos de lares de baixa renda, que não conseguem acompanhar seus pares. Onde o $F u$ turo 1 produz estratificação e resistência, o Futuro 2 também gera estratificação; entretanto, dessa vez ela é de um tipo encoberto, uma vez que as metas explícitas associadas ao $\mathrm{Fu}$ turo 1 estão agora implícitas, e os desafortunados aprendizes que tropeçam - e eles, de fato, tropeçam - não conseguem enxergar as causas do seu tropeço. Isso também causa certa indisposição, uma indisposição que, juntamente com fatores mais especificamente materiais, reside na raiz de grande parte da apatia dos jovens tão bem descrita por Gunther Kress, referenciado anteriormente, bem como em formas culturais mais destrutivas, tais como a violência contra si mesmo e contra os outros. Em outras palavras, enquanto a estratificação aberta do Futuro 1 conduz, pelo menos otimamente, à oposição e à "voz" dos excluídos, a estratificação oculta do Futuro 2 leva cada vez mais a uma variedade de estratégias individuais de "escape" que alimentam a desintegração da cultura pública. Os proponentes do Futuro 2 acabam, involuntariamente, tornando-se legitimadores dessa tendência com sua recusa em conceder valor especial ao conhecimento especializado, com sua pelo menos implícita validação de todas as formas culturais como iguais, ${ }^{6}$ e com sua celebração acrítica de formas experienciais de conhecimento.

É improvável que o cenário de "fim das fronteiras" do Futuro 2 conduza ao término do acesso ao conhecimento especializado nas elites, nas instituições e nos setores privados. O que é mais provável acontecer é a educação pública trocar o acesso desigual ao conhecimento pelo crescente acesso a qualificações, conduzindo a uma inflação de credenciais, à medida que qualificações seriam disputadas, mas teriam cada vez menos valor - seja valor de uso ou valor de troca. 
A exploração crítica do papel das fronteiras na produção e aquisição de novos conhecimentos nos permite argumentar que, a despeito de claras diferenças políticas entre neoliberais, obcecados com a promoção do mercado e escolhas individuais a qualquer custo, e os socioconstrutivistas radicais, que desejam livrar os aprendizes do que eles veem como um autoritarismo da especialização, ambos compartilham uma similaridade epistemológica de fundo. Ambos terminam com uma visão instrumental do conhecimento, com suas inevitáveis consequências relativistas. Os Futuros 1 e 2 são, no sentido epistemológico, gêmeos idênticos: eles podem diferir nas suas retóricas, nos seus meios e nos fins que almejam, mas seu resultado final é, inquietantemente, o mesmo.

FUTURO 3 - MANUTENÇÃO E CRUZAMENTO DAS FRONTEIRAS COMO CONDIÇÃO PARA A CRIAÇÃO E AQUISIÇÃO DE NOVOS CONHECIMENTOS NO CONTEXTO GLOBAL EMERGENTE

O Futuro 3 nasce da crítica e análise que fizemos dos Futuros 1 e 2 . Ele se constitui, em certo sentido, numa demonstração daquilo que a teoria social realista do conhecimento pode oferecer, e do por que ela é necessária se desejarmos que nossas alternativas para o futuro tenham algum grau de confiabilidade. O Futuro 3 é baseado na suposição de que existem tipos específicos de condições sociais sob as quais o conhecimento poderoso é adquirido e produzido. Essas condições não são dadas; elas são históricas, mas também objetivas. Enquanto sua historicidade é negada no Futuro 1 - fronteiras são dadas e assumidas como certas -, a historicidade e a objetividade que são corporificadas no papel crucial das comunidades de especialistas são negadas no Futuro 2. Quando muito, o Futuro 2 oferece uma desdiferenciação global cada vez mais sem fronteiras e fragmentada, juntamente com um otimismo ingênuo sobre o potencial dos novos movimentos sociais "de baixo para cima” e epistemologias localizadas num "Sul” metafórico (HARDT; NEGRI, 2000; SANTOS, 2001, 2008). Em contraste, o Futuro 3 enfatiza o contínuo papel das fronteiras, não como entidades dadas, seja no cérebro (neurociência), seja na mente (racionalismo a-histórico) ou 
no mundo das práticas humanas (pragmatismo e materialismo dialético), mas em definir comunidades de especialistas por domínios específicos, mas cada vez mais globais, como a base tanto para a aquisição como para a produção de conhecimento novo e para o progresso humano em geral. O filósofo contemporâneo britânico Christopher Norris descreve esse cenário, seguindo Habermas, comoo “projetoinacabadoda modernidade”.Podemos encontrá-lo, embora expresso de diferentes formas, nas teorias de ambos Max Weber e de Émile Durkheim escritas mais de um século atrás.

A última seção deste artigo explora algumas caraterísticas do Futuro 3, suas implicações e como elas podem mudar. Consideraremos, embora essa lista não seja exaustiva, os seguintes pontos:

- fronteiras e seus tipos - em relação tanto ao conhecimento e às instituições como a sua interdependência - com particular referência ao caso das disciplinas e seu futuro;

- conhecimento como real (conhecimento poderoso) e o social como real (conhecimento dos poderosos), e como as duas ideias podem ser mantidas juntas;

- currículo preferencial e modelos pedagógicos;

- implicações para as desigualdades educacionais.

\section{FRONTEIRAS E SEUS TIPOS - O FUTURO DAS DISCIPLINAS}

O ponto mais crítico a respeito do conhecimento nos próximos 50 anos será entender por que algumas formas de conhecimento tendem à especialização, enquanto outras tendem à variação ou diversificação. Essas diferentes tendências no desenvolvimento do conhecimento têm implicações críticas para o currículo e para a educação em geral. A primeira tendência coloca questionamentos sobre a sequência, ritmo e organização hierárquica, enquanto a segunda coloca questões predominantemente de escolha, do que incluir no currículo e, no limite, da ausência de qualquer critério objetivo. A conexão profunda entre a forma do conhecimento e a organização curricular é o que uma abordagem realista social ao currículo busca elucidar. 
Tornou-se moda proclamar o fim da disciplinaridade (GIBBONS et al., 1994; NOWOTNY; SCOTT; GIBBONS, 2001), no entanto as disciplinas parecem perdurar de modo quase obstinado. Sem dúvida, elas mudam e se adaptam, como o fazem todas as formas sociais robustas, mas relatos sobre $o$ seu fim são bastante exagerados. Isso não significa que novas formações disciplinares não apareçam regularmente. Elas aparecem. Porém, novas formas disciplinares invariavelmente emergem a partir de outras já existentes, primeiro na forma de "regiões" (BERNSTEIN, 2000) ou agrupamentos de disciplinas existentes em torno de novos problemas; somente mais tarde elas constituem formações separadas identificáveis, com suas próprias comunidades estáveis. A razão para isso é que, como dissemos anteriormente, as fronteiras entre os conhecimentos não são arbitrárias, e as formas internas que elas estimulam e as relações sociais que as sustentam se sedimentam ao longo do tempo em formas socioepistêmicas estáveis. Essas formas são determinadas pela força da fronteira apropriada a cada forma ${ }^{7}$ e, consequentemente, pelo modo como cada forma de conhecimento se desenvolve ou cresce.

As disciplinas diferem entre si, primeiramente, pela sua forma de avanço conceitual; e, em segundo lugar, por sua forma de objetividade. Quanto à primeira: algumas disciplinas tendem a avanços robustos e conceitualmente justificáveis. Sua estrutura de conhecimento é determinada por sua espinha dorsal em constante avanço, a qual tende à unidade (o que não significa que exista apenas uma espinha dorsal conceitual na disciplina). As implicações curriculares desse tipo de avanço conceitual são de que essas disciplinas, em sua forma madura, desenvolvem longas "hierarquias de abstração", o que Vergnaud (2009) chama de "campo conceitual”, as quais são mais bem aprendidas em sequência sob a orientação de especialistas (a Matemática e as Ciências Naturais são os exemplos mais óbvios). Podemos dizer que essas disciplinas são, em um sentido específico, ricas em conceitos. Não que elas envolvam necessariamente um grande número de conceitos (o número de conceitos não as distingue de diversas outras disciplinas). Trata-se do fato de que elas possuem longas sequências de conceitos hierarquicamente
7 Os autores referem-se aqui a formas de conhecimento ou formas disciplinares (nota do revisor técnico) 
8 Isso não nega, é claro, que, em um sentido profundo, mesmo os conceitos da ciência natura sejam sociais relacionados. Para os alunos, ficar preso em qualquer um dos degraus da hierarquia normalmente significa a interrupção do aprendizado conceitual.

Outras disciplinas tendem ao avanço por meio da variação ou diversificação dos conceitos; isso, porém, não se refere tanto a conceitos como a diferentes conteúdos ou grupos de conteúdos, apesar de usualmente existir um princípio organizador macroconceitual em ação (o "passado", ou mais abstratamente o tempo, para a História e o "espaço" para a Geografia, por exemplo). Outras disciplinas ainda desenvolvem-se de maneira prática, gerando novas habilidades e formas de fazer as coisas. O desenvolvimento prático pode se referir a novas práticas dentro das habilidades manuais tradicionais, tais como a confecção de móveis, ou a novas formas de prática conceitual, como a criação de softwares ou o projeto de websites. Conceitos, conteúdos e habilidades estão imersos em cada disciplina, mas sua importância relativa é o que as diferencia entre si.

Todas as disciplinas, para serem disciplinas, têm objetos de estudo compartilhados e, para serem robustas e estáveis, demonstram objetividade - vale dizer, elas possuem modos legítimos, compartilhados, estavelmente confiáveis de gerar verdades (YOUNG; MULLER, 2007). Verdade, nesse contexto, é uma relação estável entre objetos de estudo e uma comunidade informada de praticantes. Disciplinas, todavia, demonstram tipos diferentes, embora equivalentes, de objetividade, dependendo do fato de seu objeto ser natural ou social. ${ }^{8}$ Quanto mais social o objeto, maior é o limite para ele ser subsumido pelos conceitos da disciplina. Cada forma de objetividade, porém, deve atender aos mesmos critérios de adequação analítica - o mais simples e maior grau de subjugação aos conceitos disciplinares, sem distorção do objeto particular.

A razão para resgatar uma noção forte de objetividade, [abandonada pelos proponentes] do Futuro 2, é reinstaurar uma noção forte e confiável de especialidade (COLLINS; EVANS, 2007). A erosão da especialidade e a perda de confiança no conhecimento especializado têm sido uma consequência imprevista do relativismo do pensamento da ausência de fronteiras (MULLER, 2000). A confiança em conhecimentos confiáveis e no julgamento de especialistas tem sido esvaziada 
por um ceticismo de senso comum. Entre adultos na Europa, pelo menos entre aqueles nascidos após a Segunda Guerra Mundial, isso tem levado a uma forma peculiar de autoengano - desprezamos o conhecimento especializado e os especialistas exatamente quando nossas vidas mais dependem deles. Por exemplo, vivemos em um mundo cada vez mais medicalizado, mesmo quando os processos judiciais contra médicos crescem exponencialmente.

A juventude em nossas sociedades ainda não desenvolveu as estratégias defensivas de autoengano; muitos herdam de seus pais e dos meios de comunicação o desprezo social com relação ao conhecimento forte; como consequência, eles fracassam na escola por não tentarem suficientemente dominar algo que veem como merecedor de tão disseminado desprezo (MENAND, 1995). Mesmo enquanto o conhecimento especializado cresce rapidamente nas fronteiras de ponta, o sistema educacional inglês pode ao final falhar em produzir praticantes altamente especializados em número suficiente para o futuro, pois os jovens herdaram a sabedoria popular de que o prêmio não vale o esforço. Isso ratifica também a guinada em direção ao instrumentalismo. Se o conhecimento não é valorizado em si mesmo, então seu valor social só pode ser mensurado por sua utilidade. É instrutivo refletir que tal sabedoria popular corrosiva é totalmente ausente das economias emergentes da Coreia do Sul, China e Índia. O Vale do Silício na Califórnia não poderia ter vindo a existir sem a contratação da maioria dos seus engenheiros no Oriente. O próximo passo à frente certamente se dará no Oriente em vez de no Ocidente, se o Futuro 2 prevalecer. Assim, decisões sobre o "currículo do futuro" terão consequências de longo termo.

\section{FORMAS PREFERENCIAIS DE CURRÍCULO E PEDAGOGIA}

Dizer que vivemos em uma economia do conhecimento tem duas implicações principais para a escolarização: a primeira é a de que a economia e a sociedade que a suporta privilegiam os avanços no conhecimento, embora paradoxalmente não necessariamente em sua reprodução, como mostramos anteriormente. Isso significa que, em uma época de desenvolvimento 
acelerado de conhecimentos, a especialização e a variação (ou diversificação) tornam-se os códigos sociais dominantes, e o currículo se vê, cada vez com mais frequência, pressionado a se adaptar constantemente. Isso é menos aparente no currículo universitário porque suas comunidades de praticantes vivem próximas ao núcleo dos avanços em conhecimento - de fato, elas os impulsionam. O que isso significa, e onde se torna mais aparente, é que se define uma nova distinção entre as instituições superiores que impulsionam os avanços em conhecimentos e as que não o fazem. Essa hierarquia é atualmente marcada de forma muito rudimentar por rankings globais, e medidas bem mais sofisticadas certamente serão desenvolvidas com o tempo. Não há dúvida de que as economias e sociedades do futuro continuarão a requerer mecanismos robustos de sinalização para a classificação da produtividade dos produtores de conhecimento. A segunda implicação é a de que, mesmo nas disciplinas nas quais os conceitos têm ocupado posição secundária - como História, por exemplo - os avanços serão cada vez mais movidos por conceitos. Isso não significa que novas abordagens historiográficas brotarão do nada, mas sim que novas tecnologias digitais trarão novas formas de investigação que produzirão fatos antes impossíveis de se descobrirem, e estes exigirão novos avanços conceituais. Os mapeamentos feitos por ressonância magnética, que estão impulsionando novos avanços em neurologia, são um exemplo. Há paralelos em demografia, em física, com o Grande Colisor de Hádrons, e em nanotecnologia em toda uma gama de aplicações nas ciências.

Esses desenvolvimentos têm algumas implicações específicas para o currículo e para a pedagogia. O currículo de elite, desenvolvido em uma época em que o conhecimento mudava muito lentamente, era movido por conteúdo e, em sua pior forma pedagógica, baseado em memorização e repetição. Consequentemente, a principal alternativa ao currículo de elite, que encontra sua expressão mais sofisticada no pensamento do Futuro 2, tomou posição contra o "mero" conteúdo e a "mera" repetição - e, em sua forma mais radical, contra toda forma de estipulação de conteúdo e todas as formas de aprendizado baseado em memorização ou repetição. Essa oposição 
se exprime no consenso que emerge no Futuro 2 quanto a habilidades genéricas e currículos baseados em resultados (MANGEZ, 2008; LUNDAHL et al., 2008). Em outras palavras, ao articular uma alternativa à rigidez do Futuro 1, o Futuro 2 trocou prioridades focadas em conteúdo por prioridades focadas em habilidades. Em ambos esses formatos, especialmente no segundo, conceitos são negligenciados. Isso ocorre porque a progressão conceitual só pode ser sinalizada ou estipulada em termos conceituais, e não em termos de habilidades. Uma vez que estipulações baseadas em conceitos necessariamente envolvem conteúdo (aquilo que está sendo conceitualizado), elas se parecem demasiadamente, pelos menos aos olhos dos proponentes do Futuro 2, com as antigas prioridades baseadas em conteúdo do Futuro 1. O resultado é que, mesmo em matérias ricas em conceitos como Ciências, os currículos se tornam subestipulados no Futuro 2, como observado nas mais recentes propostas para ciência escolar da Qualifications and Curriculum Authority na Inglaterra (PERKS, 2007).

Essas tendências não constituem obstáculos intransponíveis para escolas com bons recursos, que são capazes de contratar professores com fortes qualificações em suas disciplinas, que podem preencher as lacunas. Elas são, entretanto, um problema inevitável para as escolas que atendem comunidades pobres, que não conseguem atrair tais professores. O que acontece nessas escolas é que os professores se ressentem da falta de sinais claros do currículo e ficam para trás sem perceberem, ou ignoram passos conceituais que mais tarde se mostrarão vitais (REEVES; MULLER, 2005; SMITH; SMITH; BRYK, 1998). Ao mesmo tempo, os estudantes ficam para trás até que um ponto de chegada conceitual seja atingido, e eles carecem dos recursos ou da motivação para progredir. Essa tendência é exacerbada pela favorecida pedagogia não diretiva (facilitadora) do Futuro 2, que evita dar sinais claros aos professores, especialmente no tocante à avaliação. Pesquisas contemporâneas mostram de forma inequívoca que, em matérias ricas em conceitos, uma sinalização forte na avaliação é fundamental na melhoria do desempenho dos alunos, tanto dos mais pobres como dos oriundos de lares abastados. (MORAIS; NEVES; PIRES, 2004; HOADLEY, 2007; BOURNE, 2004; MULLER; GAMBLE, no prelo). 


\section{IMPLICAÇÕES PARA AS DESIGUALDADES EDUCACIONAIS}

O Futuro 3 defende a importância de se reconhecer a "diferenciabilidade" dos conhecimentos. Seguem-se duas implicações. Primeira, formatos curriculares que são muito fixados ideologicamente apenas em conteúdo (Futuro 1) ou em habilidades (Futuro 2) negligenciam alguns assuntos, tendo ao mesmo tempo implicações na distribuição das oportunidades educacionais e do conhecimento. Segunda, reconhecer a diferenciação dos conhecimentos explicita o fato de que conceitos, habilidades e conteúdo são todos importantes e devem ser estipulados no currículo. A falha em fazê-lo significa um atraso em qualquer progresso que se tenha feito no sentido de equalizar o acesso epistemológico. Isso tem implicações tanto para a justiça social como para a viabilidade de uma futura economia baseada no conhecimento.

\section{(NOTA CONCLUSIVA)}

Enquadramos nossas previsões para o futuro da educação em torno de três cenários, e na base de uma teoria social realista do conhecimento. Indicamos nossa preferência pelo cenário Futuro 3, tanto em termos de justiça social como de fundamentos epistemológicos, e apontamos os resultados negativos que provavelmente se seguirão se os Futuros 1 e 2 permanecerem dominantes. Conforme explicamos, esses Futuros são tipos idealizados e não descrições preditivas e devem ser julgados, como Max Weber indicou há tempos, em termos de quão úteis eles são para identificar tendências e possíveis consequências indesejáveis de políticas atuais.

Por outro lado, pouco dissemos a respeito de qual Futuro provavelmente dominará os próximos 30 anos. Essa é uma questão tanto política como educacional ou cultural. É política porque se relaciona a questões de poder e à realidade de que o currículo inevitavelmente expressa o "conhecimento dos poderosos”. Enquanto a combinação neoliberal de mercados, accountability e ranqueamento institucional continuar a dominar as políticas educacionais, o Futuro 2 provavelmente dominará. O neoliberalismo está, entretanto, sob ataque, pelo menos no campo da economia e da gestão financeira. 
É difícil prever o impacto que tais mudanças terão sobre as políticas educacionais. Uma possibilidade é que um maior ceticismo sobre as possibilidades de crescimento de serviços financeiros leve ao ressurgimento da manufatura e a uma maior valorização do conhecimento baseado nas ciências. Entretanto, isso deixa aberta a questão "onde estão os mercados para esses novos bens manufaturados”?

Prever futuros prováveis é também uma questão cultural, pois, para o bem ou para o mal, limitações epistemológicas conformarão aquilo que as políticas de currículo podem fazer, quem terá o poder, e quais serão as limitações econômicas. Em certo sentido, poderíamos reescrever o famoso, porém ambíguo, aforismo de Marx sobre "homens fazendo história" ao reconhecer que as limitações epistemológicas, como as circunstâncias históricas de Marx, não são "de nossa escolha”. O presente artigo (e a tradição de pesquisa da qual ele é parte) é uma tentativa de reestabelecer a importância educacional de longo prazo dessas limitações. Nosso propósito não é o de defender uma posição conservadora ou o de voltar os olhos para um "passado de ouro"; longe disso. É o de desafiar a visão (que compartilhamos) de que o acesso ao conhecimento poderoso é um direito de todos e não apenas de uns poucos com uma teoria do "conhecimento poderoso" e de como ele é adquirido, e do papel crucial da educação formal nesse processo. Não surpreende que isso nos leve ao menos no curto prazo, a uma visão pessimista, semelhante àquela antevista por Gramsci, há 80 anos:

Estamos ainda na fase romântica da escola ativa, na qual aspectos da luta contra a educação mecânica e Jesuítica têm sido exageradamente enfatizados por razões de contraste polêmico; precisamos agora adentrar a fase racional 'clássica' e descobrir nos fins a serem atingidos a fonte natural de novos métodos e formas. (GRAMSCI, 1965, p. 1)

As possibilidades de curto prazo do Futuro 2, como a "escola ativa” de Gramsci, oferecem um cenário sedutor a governos e organizações internacionais, ao mesmo tempo em que parecem oferecer atalhos a alguns aprendizes - talvez o aprendizado real seja fácil e divertido, mais como um jogo. Estamos 
convencidos de que se trata de uma falsa alvorada, e provavelmente penalizará os menos afortunados. Não há sinais de que isso contamine nossas escolas de elite, muito pelo contrário.

Futurologia é, por sua própria natureza, uma ciência altamente inexata, uma vez que nunca dispomos de todos os fatos. Dito isso, duas coisas não necessariamente se seguirão: porque não dispormos de todos os fatos não significa que as tendências que apontamos não sejam prováveis; de forma mais pertinente, o fato dos cenários que esboçamos e suas consequências previstas terem certo ar apocalíptico não significa que eles sejam necessariamente exagerados ou errados. Como certa vez disse o escritor Philip Roth (1984):

Qualquer satírico escrevendo um romance futurista que tivesse imaginado um Presidente Reagan durante os anos de

Eisenhower teria sido acusado de cometer uma perversidade crua, desprezível, adolescente e antiamericana, quando de fato teria apenas agido como uma sentinela profética.

Que sentinelas proféticas ainda sejam bem-vindas é certamente um sinal encorajador.

\section{REFERÊNCIAS}

BERNSTEIN, B. Pedagogy, symbolic control and identity. Oxford: Rowman and Littlefield, 2000.

BOGHOSSIAN, P. Fear of knowledge: against relativism and constructivism. Oxford: Clarendon Press, 2007.

BOURDIEU, P. Science of science and reflexivity. London: Polity, 2004.

BOURNE, J. Framing talk: towards a radical visible pedagogy. In: MULLER, J.; DAVIES, B.; MORAIS, A. (Ed.). Reading Bernstein, researching Bernstein. London: Routledge Falmer, 2004.

CHRISTIE, F.; MARTIN, J. R. Language, knowledge and pedagogy. London: Continuum, 2007.

COLLINS, H.; EVANS, R. Re-thinking expertise. Chicago: University of Chicago Press, 2007.

COLLINS, R. The Sociology of philosophies. Cambridge, Mass: Harvard University Press, 2000.

DURKHEIM, E. Pragmatism and Sociology. Translation and introduction by John Alcock. Cambridge: Cambridge University Press, 1984. 
ENTWHISTLE, H. Antonio Gramsci: conservative schooling for radical politics. London: Routledge, 1979.

FITZ, J.; DAVIES, B.; EVANS, J. Educational policy and social reproduction. Oxford: Routledge, 2006.

GAMBLE, J. Theory and practice in the vocational curriculum. In: YOUNG, M.; GAMBLE, J. (Ed). Knowledge, curriculum and qualifications for South African further education. Pretoria: HSRC, 2006.

GIBBONS, M. et al. The new production of knowledge: the dynamics of science and research in contemporary societies. London: Sage, 1994.

GRAMSCI, A. Editorial. New Left Review, n. 1, p. 1, 1965.

HALL, J. A.; JARVIE, I. (Ed.). The social philosophy of Ernest Gellner. Amsterdam: Brill, Rodopi, 1996. (Poznan Studies in the Philosophy of the Sciences and the Humanities, 48).

HARDT, M.; NEGRI, A. Empire. Cambridge, Mass: Harvard University Press, 2000.

HOADLEY, U. The reproduction of social class inequalities through mathematics pedagogies in South African primary schools. Journal of Curriculum Studies, v. 39, n. 6, p. 679-706, 2007.

HUNTINGDON, S.P. The clash of civilizations and the remaking of world order. New York: Simon and Schuster, 1998.

KEEN, A. The cult of the Amateur: how today's internet is killing our culture. London; Boston: Nichols Breasley, 2007.

KRESS, G. Meaning and learning in a world of instability and multiplicity. Studies in Philosophy \& Education, v. 27, n. 8, p. 253-266, 2008.

KRONMAN, A. Education's end: why our colleges and universities have given up on the meaning of life. New Haven; London: Yale University Press, 2007.

LAUDER, H.; BROWN, Philip; BROWN, Ceri. The consequences of global expansion for knowledge, creativity and communication: an analysis and scenario. (Beyond Current Horizons). Bath, UK: University of Bath, 2008.

LUNDAHL, E. et al. Curriculum policies of upper secondary education: the Swedish case. In: EUROPEAN CONFERENCE ON EDUCATIONAL RESEARCH, 10-12 September 2008, Gothenburg. Paper... Gothenburg: ECER, 2008.

MACINTYRE, A; DUNNE, J. Alasdair MacIntyre on education: in dialogue with Joseph Dunne. Journal of Philosophy of Education, v. 36, n. 1, p. 1-19, Feb. 2002. Available online at: <http://www.readcube. com/articles/10.1111\%2F1467-9752.00256?r3_referer=wol\&tracking_ action=preview_click\&show_checkout=1\&purchase_referrer=onlinelibrary. wiley.com\&purchase_site_license=LICENSE_DENIED>. Accessed: Mar. 2016.

MANGEZ, E. Curriculum reform in French-speaking Belgium. In: EUROPEAN CONFERENCE ON EDUCATIONAL RESEARCH, 10-12 September 2008, Gothenburg. Paper... Gothenburg: ECER, 2008.

MENAND, L. Marketing postmodernism. In: ORRILL, R. (Ed). The condition of american liberal education: pragmatism and a changing tradition. New York: College Entrance Examination Board, 1995. 
MOORE, R. Sociology of Knowledge and Education. London: Continuum, 2007.

MOORE, R. Social Realism and the problem of the problem of knowledge in the sociology of education. British Journal of Sociology of Education, v. 34, n. 3, p. 333-353, 2013. DOI: 10.1080/01425692.2012.714251.

MOORE, R.; MULLER, J. The Discourse of 'Voice' and the Problem of Knowledge and Identity in the Sociology of Education. British Journal of Sociology of Education, v. 20, n. 2, p. 189-206, 1999. DOI: $10.1080 / 01425699995407$.

MOORE, R.; YOUNG, M. Knowledge and the Curriculum in the Sociology of Education: Towards a reconceptualization. British Journal of Sociology of Education, v. 22, n. 4, p. 445-461, 2001. DOI: 10.1080/01425690120094421.

MORAIS, A.; NEVES, I.; PIRES, D. The what and how of teaching and learning. In: MULLER, J.; DAVIES, B.; Morais, A. (Ed.). Reading Bernstein, Researching Bernstein. London: RoutledgeFalmer, 2004.

MORTIMORE, P. Time for bold experiments. The Guardian, Education, Tuesday 7 October 2008. Available online at: <http://www.guardian.co.uk/ education/2008/oct/07/schools.teaching>. Accessed: 2008.

MULLER, J. Reclaiming Knowledge: social theory, curriculum and education policy. London: RoutledgeFalmer, 2000.

MULLER, J. Forms of knowledge and curriculum coherence. Journal of Education and Work, v. 22, p. 205-227, 2009.

MULLER, J.; GAMBLE, J. Curriculum and structuralist sociology: the theory of codes and knowledge structures. In: MCGRAW, B.; BAKER, E.; PETERSON, P.; BAKER, E.; MCGAW, B. (Ed.). International encyclopedia of education, 3rd edition. Amsterdam: Elsevier. (No prelo).

NEWFIELD, C. The structure and silence of the cognotariat. Globalisation, Societies and Education, v. 8, n. 2, p. 175-189, 2010.

NORRIS, C. On Truth and Meaning. London: Continuum, 2006.

NOWOTNY, H.; SCOTT, P.; GIBBONS, M. Re-thinking Science. Cambridge: Polity Press, 2001.

PERKS, D. What is science education for? London: Institute for Ideas, 2007.

REEVES, C.; MULLER, J. Picking up the pace: variation in the structure and organisation of learning school mathematics. Journal of Education, v. 37, p. 97-125, 2005.

ROTH, P. The art of fiction, no. 84. The Interviewed by Hermione Lee. The Paris Review, Paris, n. 93, 1984. Available online at:<http://www. theparisreview.org/interviews/2957/the-art-of-fiction-no-84-philip-roth>. Acessed: 2016.

SANTOS, B. de S. Towards an epistemology of blindness. Why the new forms of ceremonial adequacy neither regulate nor emancipate. European Journal of Social Theory, v. 4, n. 3, p. 251-279, Aug. 2001.

SANTOS, B. de S. Another knowledge is possible. London: Verso, 2008. 
SFARD, A. On two metaphors for learning and the dangers of choosing just one. Educational Researcher, v. 27, n. 2, p. 4-13, 1998.

SHARPLES, M. et al. A Theory of Learning for the Mobile Age. In: ANDREWS, R.; HAYTHORNTHWAITE, C. (Ed.). The Sage Handbook of Elearning Research. London: Sage, 2007. p. 221-47.

SMITH, J.; SMITH, B.; BRYK, A. Setting the pace: opportunities to learn in Chicago public elementary schools. Consortium on Chicago Schools research report, 1998. Available online at: <http://www.consortium_Chicago. or/publications/pdfs/p0d04.pdf>. Accessed: 1 Oct. 2001.

TILES, M. Bachelard: Science and Objectivity. Cambridge: Cambridge University Press, 1984.

VERGNAUD, G. The theory of conceptual fields. Human Development, v. 52, n. 2, p. 83-94, Abr. 2009.

WHEELAHAN, L. How competency-based training locks the working class out of powerful knowledge: a modified Bernsteinian analysis. British Journal of Sociology of Education, v. 28, n. 5, p. 637-651, 2007.

WRIGHT, E. O. Compass points. Towards a Socialist Alternative. New Left Review, 41, p. 93-124, 2006.

YOUNG, M. Bringing knowledge back in: from social constructivism to social realism in the sociology of education. London: Routledge, 2008.

YOUNG, M. Alternative education futures for a knowledge society. In: EUROPEAN COUNCILL FOR EDUCATIONAL RESEARCH CONFERENCE, 2009a, Vienna, Austria. Keynote address... Vienna, Austria, Sept. 2009a.

YOUNG, M. Education, globalization and the 'voice of knowledge'. Journal of Education and Work, v. 22, p. 193-204, 2009b.

YOUNG, M.; MULLER, J. Truth and truthfulness in sociology of educational knowledge. Theory and Research in Education, v. 5, n. 2, p. 173-201, Jul. 2007.

\section{MICHAEL YOUNG}

Professor emérito do Institute of Education - University

College London (UCL), Londres, Reino Unido

m.young@ioe.ac.uk

JOHAN MULLER

Professor emérito da School of Education - University of

Cape Town (UCT), Cidade do Cabo, África do Sul

johan.muller@uct.ac.za 